\title{
THE EFFECT OF ALENDRONATE WITH COLLAGEN CONE IN MAINTAINING OF ALVEOLAR RIDGE HEIGHT AND WIDTH
}

\author{
Ahmad Eltabey Awad ${ }^{1 *}$, Atef Hassanein ${ }^{2}$, Abdel Mageed Elfakharany ${ }^{3}$
}

\begin{abstract}
Objective: The aim of the study was to evaluate, clinically and radiographically, the effect of alendronate with collagen cone versus collagen cone only in alveolar ridge preservation. Subjects and Methods: Thirty two Patients were selected. All patients had a treatment plan for extraction of non-restorable mandibular molar tooth. Study group (1), the sockets were filled with collagen cone(PARASORB Cone). Study group (2), the sockets filled with BonApex (alendronate sodium $10 \mathrm{mg}$ ), Study group (3), the socket filled with collagen cone in addition to alendronate and Control group (4), the socket left empty and closed. In this Study, Width and height of the alveolar ridge were measured in addition to bone density. Results: Alveolar bone height at the buccal side heights was decrease in all group but more in control group. Collagen+ Alendronate showed the least decrease in lingual height followed by collagen only group. Alveolar bone width was assessed in all groups collagen+ alendronate and collagen only showed the least decrease in width measurements. In this study Collagen+ Alendronate and collagen alone showed the higher increase in bottom measurements. Collagen + Alendronate and collagen only showed the highest increase in density measurements. Conclusion: The use of collagen sponge with alendronate in the present study, significantly minimized ridge resorption in all dimensions
\end{abstract}

KEYWORDS: Collagen, Alendronate, Socket preservation.

\section{INTRODUCTION}

Loss of natural teeth is followed by bony changes in the jaws. This bone change occurs immediately after extraction due to the absence of stress applied in this area ${ }^{(1)}$. Bone resorption has been suggested to occur in 2 phases, in the first phase, bone bundle is rapidly resorbed and replaced with woven bone leading to a great reduction in bone height, especially in the buccal aspect of the socket ${ }^{(2)}$.
The second phase, A natural process of bone remodeling starts immediately after a tooth extraction, where the remaining bone begins to resorb. Thus, socket preservation techniques help to decrease this problem by minimize the trauma to surrounding tissues and preserve the ridge by adding graft material into the socket that will serve as a scaffold for bone cells for better repair and healing of the socket ${ }^{(3)}$.

1. Master Candidate, Oral and maxillofacial Department, Faculty of Dental Medicine, Boys, Cairo, AL-Azhar University

2. Assistant Prof, Oral and maxillofacial Department, Faculty of Dental Medicine, Boys, Cairo, AL-Azhar University

3. Professor, Oral and maxillofacial Department, Faculty of Dental Medicine, Boys, Cairo, AL-Azhar University

-Corresponding author: dr.tabey@gmail.com 
Collagen sponge preserves the capacity of the blood clot, but it also prevents soft tissue collapse into the socket, which lacks the support of alveolar bone ${ }^{(4)}$. Collagen sponges are stable and moldable cone-shaped biomaterials made from natural collagen capable of facilitating blood clot formation.

A clinical study, collagen sponge and xenogeneic bone were applied in dental sockets after extraction for ridge preservation in twenty patients. The results xenograft prevented the horizontal resorption of the alveolar ridge. Collagen sponge blocks the infiltration of soft tissues and increase enhancement of bone fill ${ }^{(5)}$.

Alendronate is a widely used bisphosphonate that has been administered systematically to reduce post extraction alveolar ridge resorption to $50 \%$ of the original loss in animals as well as in humans. It has also been administered locally to prevent bone loss due to periodontitis in animal models. The local effect of alendronate with intra-alveolar collagen sponges immediately after extraction of teeth prevents post-extraction alveolar ridge resorption in study performed in twenty patients with age between 30 and 65 years. The patients were divided into two groups. The statistically significant bone loss prevented by the collagen alone was $22.8 \%$ and in collagen with alendronate group was 44.38 $\%$ at the end of 4 months ${ }^{(6)}$.

\section{SUBJECTS AND METHODS}

In this current study, 32 patients were selected from those attending Outpatient Clinics of Oral and Maxillofacial surgery Department at faculty of Dental Medicine, Al- Azhar-University, Boys, Cairo. Patients should have badly broken unrestorable teeth, indicated for extraction. Inclusion criteria:

Age between 20 and 45 years old, good general health \& good oral hygiene and Presence of a hopeless tooth requiring extraction. Exclusion criteria: pregnancy or patients in lactating period, patients with systemic diseases that affect bone healing such as uncontrolled diabetic patients, patients with acute infections, uncontrolled generalized periodontal disease and Patient with history of chemotherapy or radiotherapy. . Protocol was approved by the Local Ethical Committee of Al-Azhar University (OMS2018). The patients were divided randomly into 4 equal groups, each group included 8 patients. group (1) the sockets were filled with collagen cone group (2) the sockets filled with (alendronate sodium) group (3) the socket filled with collagen cone in addition to alendronate and group (4), the socket left empty and closed with stich. In the present study, the following measurements were recorded: Width of alveolar ridge. Vertical (buccal and lingual) measurements. Bone density.

\section{RESULTS}

Clinical evaluation: The degree of pain was evaluated in all groups with VAS scale, there was no severe pain detected in all patient.

Radiographic evaluation: Vertical bone height was assessed with CBCT, Horizontal measurement was done to determine width of bone. In addition, bone density was measured to determine the efficacy of synthetic bone (Fig. 1 and 2)

Buccal bone height: After extraction, 3and 6 months; there was no statistically significant difference between buccal heights in the groups.

Lingual bone height: At base line; there was no statistically significant difference between lingual heights in the groups. At 3 and 6 months; there was a statistically significant difference between lingual heights in the groups. Collagen+ Alendronate showed the least decrease in lingual height followed by collagen only group.

Socket Bottom: There was no statistically significant difference between Bottoms in the groups.

Collagen+ Alendronate and collagen alone showed the higher increase in bottom measurements. 
Width of socket: There was no statistically significant difference between width in the groups. Collagen+ Alendronate and collagen alone showed the least decrease in width measurements.

Bone Density: There was no statistically

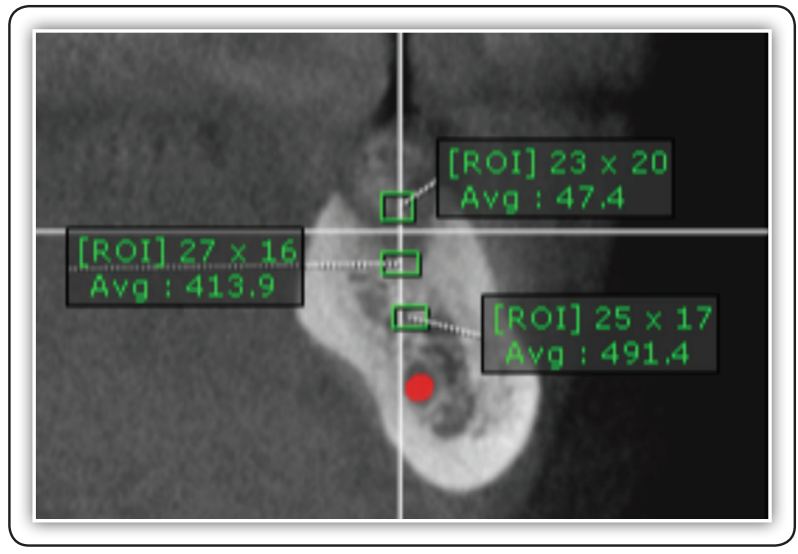

FIG (1) Showing bone density significant difference between densities in the groups immediately after extraction and 3 months. At 6 months there was a statistically significant difference between density in the groups. Collagen + Alendronate and collagen alone showed the highest increase in density measurements, Fig 3.

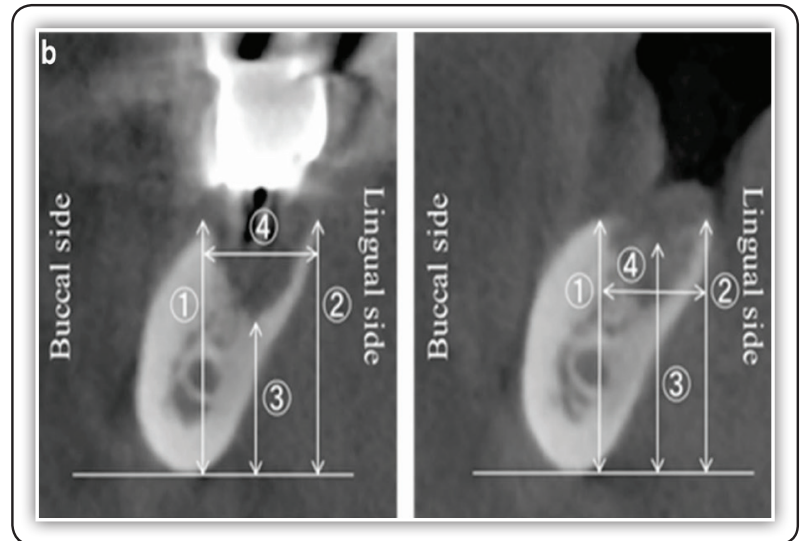

FIG (2) Showing bone width \& height

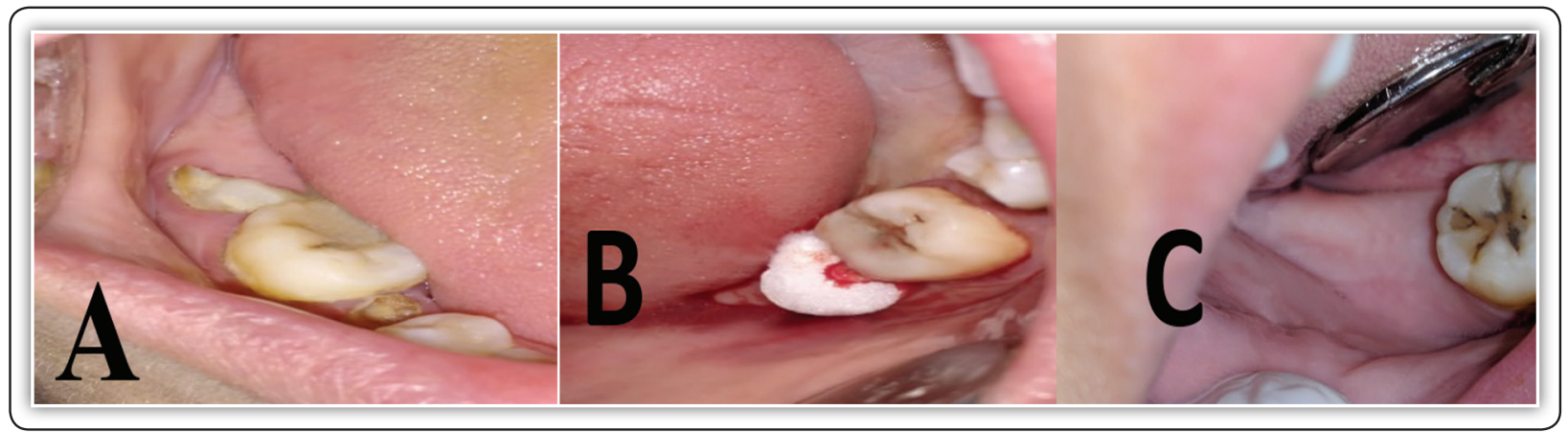

FIG (3) (A) preoperative (B) collagen\&alendronate

(C) postoperative 6 months

\section{DISCUSSION}

Alveolar ridge undergoes resorption in both vertical and horizontal aspects. This ridge loss starts after extraction and continues throughout life, its fastest rate during first three months, and then the rate decreases gradually. This problem may prevent teeth restoration or implant insertion. So the aim of present study was done as a try to overcome and to compensate this resorption with alendronate and collagen.
Bone reduction, is a progressive and irreversible, which may involve vital structures like maxillary sinus and inferior alveolar canal. That may lead to difficulties on restoring teeth with removable dentures rather than impossible implant placing in such cases except after aggressive surgical procedures before implant placing to restore both horizontal and vertical dimensions. So, socket preservation should be performed ${ }^{(7-9)}$.

In the present study an anti-osteoclastic drug of bisphosphonate group (Alendronate) was applied 
locally with collagen cone, that acts as a carrier to decrease this immediate post-operative resorption of bone. The collagen cone when placed inside the extraction socket, provides dimensional stability to the socket and prevents the collapse of the socket walls. Moreover collagen when used with alendronate causes slow release of the drug over a prolonged period of time ${ }^{(10)}$.

Demonstration of the advantage of the semipermeable property of collagen cone, which allows diffusion of nutrient molecules from the external environment into the repair site and permits the diffusion of important wound-derived neurotrophic factors ${ }^{(11)}$.

Radiographic assessment was done in the present study by CBCT taken immediately after extraction and at three and 6 months to assess the differences in ridge width and height and bone density in all groups. Many studies supported using CBCT as a reliable and accurate diagnostic aid to assess ridge width and height ${ }^{(12)}$ and bone density ${ }^{(13,14)}$.

Several studies ${ }^{(15-18)}$, showed that reduction, but not complete elimination of the vertical and horizontal bone resorption compared to unassisted socket healing after alveolar ridge preservation procedures. The present findings confirmed that complete preservation of the alveolar ridge dimensions after tooth extraction cannot be obtained with graft materials. However, in contrast with our study, the previous study determine the loss of buccal side level was more pronounced than on the lingual counterpart ${ }^{(19-21)}$.

Our study indicated that socket preservation using combination of collagen cone with alendronate with a flapless approach minimized ridge resorption in all dimensions in comparing to other findings recorded after tooth extraction without alveolar ridge preservation. Loss of bone recorded at the buccal side of the alveolar ridge are within the range of results reported in previous studies testing various alveolar ridge preservation surgical techniques and materials $^{(22,23)}$.

\section{CONCLUSION}

The use of this combination of collagen sponge with alendronate in the present study, were effective in socket preservation and significantly minimized ridge resorption in all dimensions and was able to increase the quality of the novel bone and enhance the rate of bone formation.

\section{REFERENCES}

1. Sager M, Darwish S, Melek L, The effect of bioscaffold alvelactm in preservation of alveolar bone after extraction of teeth (clinical and radiographic study). Alexandria Dent J 2015;2:22-6.

2. Pagni G, Pellegrini G, Giannobile W, Rasperini G. Postextraction alveolar ridge preservation: biological basis and treatments. Int J Dent. $2012 ; 1: 1-13$.

3. Huynh-Ba G, Pjetursson BE, Sanz M Cecchinato D, Ferrus $\mathrm{J}$, Lindhe $\mathrm{J}$,et al. Analysis of the socket bone wall dimensions in the upper maxilla in relation to immediate placement.Clin Oral Implants Res2010; 21: 37-42.

4. Dagalakis N, Flink J, Stasikelis P, Burke J, Yannas I. Design of an artificial skin. Part III. Control of pore structure. J Biomed Mater Res.1980 ;14:511-28.

5. Kim Y, Yun P, Lee H, Ahn J, Kim S. Ridge preservation of the molar extraction socket using collagen sponge and xenogeneic bone grafts. Implant Dent. 2011;20:267-72.

6. De Sarkar A ,Singhvi N, Jayaprasad N. Shetty T, Shetye $\mathrm{O}$, et al. The local effect of alendronate with intra-alveolar collagen sponges on post extraction alveolar ridge resorption: a clinical trail. J Oral Maxillofac Surg 2015; $14: 344-56$

7. Weijden FVD, Dellacqua F, Slot DE. Alveolar bone dimensional changes of post-extraction sockets in humans: a systematic review. J Clin Periodontol. 2009; 36:1048-58.

8. Horowitz R, Holtzclaw D, Rosen PS. A Review on Alveolar Ridge Preservation Following Tooth Extraction. J Evid Based Dent Pract. 2012; 12:149-60.

9. Monjo M, Rubert M, Wohlfahrt JC, Ronolt HJ, Ellingsen JE, Lyngstadaas SP. In vivo performance of absorbable collagen sponges with rosuvastatin in critical-size cortical bone defects. Acta Biomater 2008;6:1405-1412.

10. Spolidorio LC, Marcantonio E Jr, Spolidorio DMP, Nassar CA, Nassar PO, Marcantonio RA et al .Alendronate therapy in cyclosporine-induced alveolar bone loss in rats. J Periodont Res 2007; 42:466-473. 
11. Pagni G, Pellegrini G, Giannobile WV, Rasperini G. Postextraction Alveolar Ridge Preservation: Biological Basis and Treatments. Int J Dent. 2012; 26:1-13.

12. Norton MR, Gamble C. Bone classification: an objective scale of bone density using the computerized tomography scan. Clinical Oral Implants Research. 2001;12:79-84.

13. Aranyarachkul P, Caruso J, Gantes B, Schulz E, Riggs M, Dus I, Yamada JM, Crigger M. Bone Density Assessments of Dental Implant Sites 2. Quantitative Cone-Beam Computerized Tomography. Int J Oral Maxillofac Implants. $2005 ; 20: 416-24$

14. Razi T, Niknami M, Alavi Ghazani F. Relationship between Hounsfield Unit in CT Scan and Gray Scale in CBCT. J Dent Res Dent Clin Dent Prospects. 2014; 8:107-10

15. Weng D, Stock V, Schliephake H. Are socket and ridge preservation techniques at the day of tooth extraction efficient in maintaining the tissues of the alveolar ridge? Euro J Oral Impl. $2011: 4$; 59-66.

16. CHF Ha“mmerle, Araújo MG, Simion M. Evidence-based knowledge on the biology and treatment of extraction sockets. Clin. Oral Impl. Res. 2012, 23 , 80-82

17. Vignoletti F, Matesanz P, Rodrigo D, Figuero E, Martin C, Sanz, M. Surgical protocols for ridge preservation after tooth extraction. A systematic review. Clin. Oral Impl. Res. 2012: 23; 22-38.
18. Wang R, Lang N. Ridge preservation after tooth extraction. Clin. Oral Impl. Res. 2012: 23; 147-156.

19. Willenbacher M, Al-Nawas B, Berres M, Kammerer P, Schiegnitz E. The effects of alveolar ridge preservation: A meta- analysis. Clin Implant Dent Relat Res.2015; 6; $1248-1268$.

20. Schropp L, Wenzel A, Kostopoulos L, Karring T. Bone healing and soft tissue contour changes following singletooth extraction: a clinical and radiographic 12-month prospective study. Int J Period Restor Dent 2003;23: 313-23.

21. Roe P, Kan JY, Rungcharassaeng K, Caruso JM, Zimmerman G, Mesquida J. Horizontal and vertical dimensional changes of peri-implant facial bone following immediate placement and provisionalization of maxillary anterior single implants: a 1-year cone beam computed tomography study. Int J Oral Maxillofac Implants. 2012 ;27:393400 .

22. Mardas N, Chadha V, Donos N. Alveolar ridge preservation with guided bone regeneration and a synthetic bone substitute or a bovine-derived xenograft: a randomized, controlled clinical trial. Clin. Oral Impl. Res. 2010. 21; 688-698.95.

23. .Kim D, Kim, Hyun C,Hong JU, Shin, Seung et al. Validity of Collagen Plugs for Ridge Preservation in a Canine Model. Implant Dentistry.2017; 26:165-72. 